IBT Journal of Business Studies

Volume 14(2), 198-208, 2018

\title{
Benazir Income Support Programme (Bisp): Its Benefits and Implications
}

\author{
Muhammad Ali Pasha ${ }^{l}$ \\ Parveen Shah ${ }^{2}$ \\ Saleem.Rahpota ${ }^{3}$
}

\begin{abstract}
Poverty is defined as a state as a result of economic, social and demographic factors when meeting a certain criterion. For reduction of poverty, a social protection programme is created and initiated that refers to a mechanism by mean of which certain policies and strategies are put into action to provide facilities to the underprivileged section of the country in order to enhance their standard of living and household livelihood and consumption. This research paper is focused on the benefits and implications of BISP in the country of Pakistan which is a developing nation and has been facing the challenge of poverty. Firstly an overview on the term of poverty is done followed by overview on social protection programme from a global and national perspective. Then overview of BISP and its goals and process is done. Then the study looks into the positive aspect on the implementation of the scheme and what its shortcomings are that has affect its success. Many challenges and incompetency have been discussed while providing ideas for resolution as well.
\end{abstract}

Keywords: Benazir Income Support Programme, BIPS, Poverty, Alleviation of Poverty, Reduction of Poverty, Social Protection Programme, Women Empowerment

1- University Of Sindh, Jamshooro, muhammadalipasha@gmail.com

2- Shah Abdul Lateef University,vc@salu.edu.pk

3- Shah Abdul LateefUniversity, saleemrahpoto64@hotmail.com 


\section{INTRODUCTION}

There are many definitions that reflect the idea of social protection and it is referred to a collection of programmes and policies that are aimed to reduction of vulnerability and poverty in the concerned region. It has been found that around the globe, in many underdeveloped and developing countries, the inadequacy and underdevelopment of different systems of social protection haven't been able to contribute to the society and as a result of this, a major part of the population has been exposed to increased levels of excessive risks of poverty and insecurity.

Then it comes to the country of Pakistan, many events have occurred such as natural disasters: earthquakes, rains and floods and such as political disturbance and change of governing bodies. All these require immediate and effective services of social protection programmes and services for men and women alike but more focus on women as they are termed as more vulnerable in the country.

One such social protection programme is known as 'Benazir Income Support Programme (BISP)' whose aim is to work on women's protection in the country of Pakistan. It has provided them with a social safety net system wherein providing the women with the opportunities to have accessibility to sources of income and be in position to make their future better. It has its share of ups and downs when it came to the effectiveness of the program primarily to due to inadequacy of concerned governing bodies and unavailability of support and aid for the same. Though there has been some results obtained showing a part of women population residing in interiors part of Southern Punjab and Sindh have benefitted from this program but then afterwards no clear evidence is present on the increase in the rate of success and further improvement. This may attribute to the fact that this programme's aim was no doubt appreciative but means weren't there to take this mission forward and expand it effectively (Irz et al., 2001; Bahram et al., 2017).

\section{LITERATURE REVIEW}

\section{Overview of Poverty}

There have been a number of studies and researches on poverty measurement which has analyzed what are the trends of poverty existing and what is the extent and scope of poverty in the regions. It is said that Poverty comes into existence by various processes and means of social, economic and political factors. Then there is scope to address poverty via means of different factors of population like health status, income levels, educational levels, income distribution, gender and its discrimination, geographical location, class level in the society, living standards and much more. These factors are not one dimensional; instead they are multi-dimensional and also are connected with the national and international scopes making it a national as well as an international issue as well. Similarly when it comes to Pakistan, it has a great challenge facing the issue of poverty and has been developing schemes for reduction of poverty as this has been a problem faced by Pakistan for about $25+$ years. It has been an increasing tougher issue which needs immediate resolution and planning strategies and actions (Irz et al., 2001).

\section{Need of Social Protection Programme and Strategies}

It is stated that around the globe, it is seen that major part of population in the developing countries, reside in the rural areas as comparison to urban areas. In addition, the rural areas are less equipped for a better lifestyle and have fewer facilities for households as well in comparison to urban areas as highlighted by (World Bank, 1990). It is further highlighted by (Todaro et al., 2000) that in the regions of Asia and Africa about 89-90 percent of the population is located in the rural parts of the regions and when it comes to Pakistan, poverty in rural areas is much more than the lower class in the urban part of 
the country.

\section{Social Protection Programs and the Globe}

Poverty is reflected as a profound and defined economic and social development state. This is realized on the international scale where international regulatory bodies have produced reports stating the same and they have been presented by (ILO, 2003; IFAD, $2001 \&$ World Bank, 2000). There has been exclusive focus on poverty by (World Bank, 2000) and reports have been produced timely. Also there has been report by International Fund for Agriculture (IFAD, 2001) where the statements presented have been taken as a motto to resolve the issue of poverty and eradicate it from the rural areas completely. Then there is report by International Labor Organization (ILO, 2003) at a conference that reflected on the idea that poverty has multi-factors connected with it in terms of social, economic and demographic with the focus on exploitation and eradication of poverty in the poor regions of the developing countries.

\section{Social Protection Programs and Pakistan}

Reduction of poverty is crucial to the economic development in a country for which efforts are needed to be put forward for reducing the poverty which can be done by increasing the income of household. It is important to understand that poverty alleviation and reduction are of majors concerns when it to issues and challenges faced by the developing countries around the globe. This is the goal of all the policies and establishment of the public sector in Pakistan. There have been attempts made by them to reduce poverty in order to stimulate the economic growth and is trying to achieve this through means of improving the performance and condition of labor market and workforce, providing education and medical facilities of good quality, creating opportunities for sources of income and providing jobs, building new infrastructures and enhancing old ones and capitalizing networks and synergies, having facilities available in times of crisis, financial and non-financial and deal with natural disasters as well.

The impact of the world poverty has been on the developing countries as well and Pakistan is also a developing country that has the challenge to reduce poverty as well. It is observed that during the course of time around the $1960 \mathrm{~s}$, there was a great increase in poverty, then it fell weak in the course of time around 1970s and 1980s, then it came back in the course of time during 1990s and fell again in the course of time during 2000s (Amjad et al, 1997; Ali et al, 1999; Jafri etal, 1999; Arif et al, 2006) and again there is an increase in the following years. This shows that the trend of poverty isn't constant and the same is highlighted by (World Bank, 2000) as well and this also implies that the task of poverty reduction is a continuous task which needs attention always. There are many factors that affect the supply of food in the country and these include labor force, employment rate of allowance, wage rate, asset ownership and accessibility, inflation factor, dependency ratios, all these classified as macrolevel factors. In Pakistan it is noted that most of the poverty is residing in the rural areas and most of them are remote and very far away from basic civilization facilities. There was a development of an Asian development bank (ADB) strategy for the management of poverty reduction procedures in the country and support the other related aiding programmes. Their plans include good governance of activities including job creation, source of income availability, rural development, and social development such as health, education, sanitation, food and water supply, social protection and raising living standards. Also in addition, there is need for sustainable management of environment in the regions as well (ADB, 2002).

There is a focus on the public policies and programmes for poverty reduction by (Kemal et al.,) wherein he is attempting to explain and describe the instruments and tools for reducing poverty. There were planning to increase the size and scope of the establishments to run the mechanisms for poverty reduction and target a much bigger portion of the population. Then taxation system should be in a way 
that proves to be constructive to all the classes of the society. Then it shall be made sure that equal opportunities should be made available to the lower class of the society so that the poor people have an equal shot on making the lives of their families better. There was a survey done in the village of the Punjab, measurement of a number of variables in relation rural families was done as well to identify which factors are crucial for raising their living standards (Malik, 1996). Also how these people contribute in achieving the same and what opportunities shall be provided to them so that they can better their lives and help in the reduction of poverty.

Then another study was conducted by (Chaudhry et al., 2003) wherein elements of scope, status, complicity, form, nutrient and other micro factors relating to poverty were observed. (Khan, 2009) The statistical tools were used to identify their relationship with poverty and accordingly decide among them the primary and secondary elements. This study represented results stating there is a need to establish better economic platforms, there shall be an increase in production of agricultural commodities and also by improving economies of agriculture and non-agriculture scope. The quality of life and its standards are to be enhanced by proving better facilities for education and its institutions, healthcare and medical institutions as all these are stated to be strategic and crucial for alleviation of poverty.

Then another study was conducted in the region of Pakistan by (Chaudhry \& Etal, 2005) that the lands are to be taken care of and expanded in order to provide platform for equality and equal option for earning income and along with include development of animal husbandry, of demographic factors, of social and economic factors, all are needed to be done in order reduce poverty, especially in the remote areas in the region of Pakistan. There is another study by (Chaudhry et al., 2006) which also emphasizes on the reduction of poverty in the urban sector of the region as well which can be achieved via mean of good governance as well and also the management of economic, social and demographic infrastructure will also play its role as well.

Then another study has been done by (Arif, 2006) where the programmes of national anti-poverty was observed present through the form of contributions made through charity, and in addition of services via means of micro-financing as well reflected from surveys of Pakistani socio-economic surveys (PSES). It has been identified that the target of micro-financing services is not the poorest level of the region showing restrictions to access to financial services for the lowest class of the society. Then there is a study on Zakat collection and distribution for which proper mechanisms shall be there to ensure its effectiveness and lead to reduction of poverty as well while planning and implicating different policies for the same. B.

\section{Overview of Benazir Income Support Programme - BISP}

The purpose of the social safety net programmes is mainly to allow for reduction of the negative impact of poverty on the concerned part of the population and this is one of the important initiatives taken by government. The same case has been observed in the country of Pakistan. During the course of time around the years 2007-2008, there was a notable increase in the oil prices, rise in the primary product prices in the markets: both domestic and international leading to heightened inflation going from single to double digits that cut off the purchasing power almost to half weakening the prospect's position. These circumstances called for an immediate and effective action by the government of Pakistan.

Then BISP came up in the scene as a solution to the arising problems in order to provide direct, timely and effective relief and aid to the affected, under-privileged and need part of the region in the country. A. it was established in all the provinces of Pakistan (Punjab, Sindh, Baluchistan and KhyberPakhtunkhwa), as well as Federally Administered Tribal Areas (FATA), Azad Jammu and Kashmir 
(AJK), Gilgit Baltistan and Islamabad Capital Territory (ICT) by the then prime minister of Pakistan: Yousuf Raza Gillnai in the year of 2008 with the primary goal of reducing poverty in the country. It also provide monetary aid in emergencies for quick relief. And as per a simple outline, it was decided that about $3 \%$ of gross domestic product is to be spent on BISP. B.

The start of project was initiated with the primary aims of poverty alleviation along with women empowerment in the under-privileged areas of the region in the country. The starting budget for the programme was 34 billion rupees: about 425 million US dollars for the course of time from 2008-2009 with the idea of helping out about 3.5 million families spread over the country. There were many challenges in the beginning as firstly they had no portal of adequate, correct and updated data available to identify the quantity and other related information of people living in the under-privileged regions of the country and as an immediate solution, the parliamentarians were asked to work out the number of the concerned individuals and a lot of trust was put into the. As a simple outline, a form was devised and asked the respondents to fill them up and then their eligibility and ineligibility will be decided on for further the aid and then another improved process was put into place via mean of refined targeting process with the idea of minimizing possible errors on the enrolment of the concerned individuals and there is a platform available for equal and just opportunities for enrollment.

The scheme of BISP is providing other services as well including initiatives for health insurance coverage such as pregnancy, diagnostic laboratory tests, hospitalization, daycare treatment, compensation in cases of natural disaster and accidents for family of the concerned/beneficiary individuals up to an amount of 25 thousand rupees per family over a year; initiatives for development of comprehensive skills, short courses and vocational training workshops for the enrolled individuals. Also they offer loan of 3 hundred thousand rupees which is interest free via computerized balloting to individuals to create their source of earning wherein guidance and support are also provided to ensure that the mean of earning income is appropriate and has potential to be successful and this programme is known as Waseela-e-Haq.

There is a proper feedback system instilled in this scheme as well where after a certain period of time ( 2 years, re-assessment of the enrolled individuals and families is done to see where they still meet the criteria or not for the further aid by the scheme or not.

\section{Objectives of Programme}

The following are the objectives of this scheme:

- An initiative for compensation of low income families because of reduced purchasing power

- Grant of cash (about 1000 rupees per month)

- There will be 1 receiver (beneficiary) from 1 family to accept benefits

- Providing women empowerment as giving a chance to female member of the family to be the receiver (beneficiary)

\section{Stake-holders of the Programme and their Roles}

- Operating Wing of BISP

- Ministry of Finance

- Organization for Data Entry

- Agency for Payment Management

- Beneficiaries of BISP

\section{Selection of Beneficiary}

The selection of the beneficiaries from the poor households is done on the basis of meeting with the criterion of a defined poverty score and then within these households, families are being selected and their composition is one of the following compositions: 
- Husband, wife with no children

- Husband, wife with unmarried children

- A widow with or without her unmarried children, living alone or with her parents/relatives.

- A divorced woman with or without her unmarried children, living alone or with her parents/relatives

It is devised that the women in the families are entitled to receive cash and these women are the wives when there is presence of husband and when there is no husband as when the woman is widowed, separated or divorced.

\section{Stages of BISP Module - Project Cycle}

Stage 1: Target aims at Data Collection on household-welfare using Survey Mechanism:

Firstly the data is collected on the consumption of household (such as medicine, food, school fees and utilities etc.). The estimation of income and expenditure helps in understanding the extent of poverty and helps in finalizing the decision for cash assistance. The data collection is done via interviewsurvey where respondents are families of the poor household in relation to their consumption of household.

\section{Stage 2: Validation \& Verification of Data}

When the surveys are done, they are carried through interview and questionnaire forms provided by the governing and regulatory bodies for BISP. Then the agency for data entry filed all the collected data and creates a list of the targets for the programme in the programme management information system (PMIS) software and validation of data is done.

\section{Stage 3: Selection of Beneficiary using Poverty Scorecard}

With the software of PMIS, the deserving households are identified and then the women from each family are picked as beneficiary. This is achieved with the help of Poverty Scorecard approved by the World Bank that is based on the outline of proxy means testing (PMT) that helps in carrying out survey for poverty on a nationwide scale to identify the poor families. The forms created in the stage 2 sue PMT basis where a weight-age is assigned with each question and the questions cover the areas including are household roster, living conditions, status of house, ages of members and possession of any agricultural land or livestock and other related information about the potential beneficiaries and their families. The eligibility of beneficiary is decided when its score is less than or equal to cut off figure as fixed in the system. These are cross-checked with the help of by National Database and Registration Authority (NADRA) and made digitized. It is said that about 5 million and more beneficiaries have identified and helped.

\section{Stage 4: Payments by BISP}

Firstly, the payment was done via means of Pakistan-post via means of money orders and also direct payments have been made as well depending on the circumstances. In order to maintain social accountability and transparency of the payment system, each related detail is digitized and available in BIPS website. Then technologically oriented payment systems have been explored and implemented as well like such as Smart Cards being issued by NADRA and where arrangement of payments have done by banks via mean of a network of franchises with a core application for banking in this regard.

\section{Stage 5: Influence of Women Empowerment}

The women are provided a platform where are in a position to make plan and take decision on the consumption on factors related to household. They are empowered as they stand as an equal contributor towards economic drive in the region. 


\section{Stage 6: Case Management}

Then each beneficiary is taken as an individual case to be managed and assessed for further action and to take decision for providing further monetary and non-monetary aid.

\section{ANALYSIS \& DISCUSSION}

It is established that BISP did bring a ray hope in the country like Pakistan where problem of poverty is quite evident and a growing problem. It provided the under-privileged part of the regions of the country with opportunities to better their livelihood and standard of household via mean of cash transfer on certain terms and conditions. But along with the scheme, there has been some issues and varying difficulties with the effectiveness and efficiency of the scheme. Some of them have been highlighted as follows:

\section{Non-operational of case management system}

It is seen that since the establishment of the BISP scheme, there has been lacking in the developing and executing the case management system in the scheme specially at the grass-root level and this is proving to be inefficient when it comes to address the issues of the ones who have included and those who haven't been and this is a big drawback for the scheme. This reflects that the idea of providing equal opportunity to every deserving individual may become difficult.

\section{Inefficient Flow of Information}

The presence of the management of the scheme isn't much evident at the grass-root level of the programme, this cause a hindrance/difficulty in the process of information reaching from one party to another party and therefore resolution of issues and cases also take much more time and sometimes get ignored as well which is a big drawback as this will be a hurdle in fulfilling the goal of the scheme itself.

\section{Weak Communication System}

It is seen that the communication system at the scheme is efficient and therefore producing difficulties in connecting the decision makers of the programme with the affected individuals and provide attention their cases and issues.

\section{Need of Networking and Synergy}

There is an immense requirement for the scheme of BISP to get connected with other programmes with similar outlook and goals in order to strengthen its own programme and expand into other aspects as well and at the same time, contribute by providing its share of services as well. In addition, expert advices and suggestions can also be gained by the other stake-holders of the other programmes. The development of frame-work and strategies to take the scheme further can be achieved as well. The BISP needs to be however first to be efficient enough that they are in a better position to put forward a proposal for networking and synergy.

\section{Need of Efficient Feedback and Assessment Mechanism for BISP Scheme}

It is highly advisable for any system or scheme to be efficient and smooth, there shall be a mechanism instilled that allows to provide feedback on a timely basis while assessing the effectiveness and quality of the schemes. The BISP needs an assessment mechanism in order to monitor, observe and evaluate the scheme and accordingly, improve the design of the scheme and devise improvements so that the execution of the scheme is done on fair and sincere grounds. This will help is catering the needs of deserving candidates and the number can increase as well. This however is a big lacking in the scheme of BISP proving to be one of the main reasons of it not being much successful as accountability calls for responsibility which is lacking in the management of BIPS. 


\section{Need of Technological Advancement}

It is seen that with the progress of time, technology has come over the ways of conducting activities. The BIPS has given way to technological advancement in some of the districts but yet there is much room for further improvement and the number of districts is lower. Also there has been use of branchless banking for providing monetary assistance to the concerned individuals but again in some districts only. This calls for establishment of this technological advancement in other remaining districts as well in order to have homogeneous execution of scheme everywhere otherwise these discrepancies lead to non-function of many scheme services. A new system mechanized and technological will also smooth the transfer of funds to the concerned parties with less chances of carelessness in between.

\section{Dissemination of Information}

There is a requirement to disseminate adequate information at all the necessary levels in the system. It is the right of the concerned individuals to know how the system works and how they will be provided aid and support. They also have the right that all their necessary and adequate queries are answered and related information is provided them.

\section{Need of Building Efficient Database}

It is important that a proper database is established for BISP and it is timely updated as this is crucial for planning and strategies making for the development of various projects and reforms in the public sector in order to improve the scheme and provide better facilities and opportunities for the women out there in distress and improving their livelihood. This will also able to help maximize the benefit of the investment in the database which is update via means of collection of data techniques (questionnairesurvey).

\section{Need of Offering More Opportunities}

It is highly needed that the scheme of BIPS is expanded by providing more opportunities in addition to the services being provided including cash transfer on certain terms and conditions, provision of vocational training, technical education and workshops. Furthermore, they need to establish more offices, centers for training and workshops for enhancement of skills as well. There is a dire need for this as in the country of Pakistan; no number of financial and non-financial aid and support will be sufficient enough. It will be also a good to increase the amount of money being granted or if not, that at least it needs to be sufficient enough to meet the daily needs and requirements smoothly.

\section{Assessment and Evaluation Mechanism of Beneficiaries}

This is an important step that the ones who have received the monetary and non-monetary aid, are being assessed and evaluated to see what has been the rate of success and whether have move ahead the defined criterion line of poverty or not and whether they are in a position to sustain and improve their living standards or not. This is highly important because at times when there isn't a proper check and balance; many who have been helped may continue ask for the aid even if they don't need it anymore. This will also put the other deserving individuals at the back seat as well which will hurt the goal of this scheme.

\section{Corruption}

This is a very common and most damaging problem for any scheme where an entire established system can go to ashes if there is one drop of corruption involved in the scheme. Also this ring a bad name to the BIPS as well and the trust in the system will be lost as well. Also all the funding which is supposed to go for a good cause will end up in the pockets of the wrong people. 


\section{Intervention and Support by Government}

It is important that from time to time, the government is on continuous strive to provide the scheme of BIPS with its support and aid to have it up and running efficiently. There is need of such interventions and investment by government in this scheme and other similar programs as well. The government has a duty to serve the people of the country and extend an extra hand help to those who are underprivileged specially.

\section{Need of Acceptance on the Importance of Women Empowerment}

The societal thinking in the country still needs much exposure in this regard that women empowerment is needed and significant for the economic growth of the country as women form a big part of the population as well. Therefore their roles count a lot in the development of the social, economic and demographic growth of the economy as well.

\section{RESEARCH GAPANALYSIS}

In overall scenario it can be said that the main issue with the low success of BIPS attributes to the main cause of not putting forward efforts to make it more efficient and effective. They didn't take of loopholes and didn't care of lacking present in the system. In this way the scheme instead of getting better, is getting worse because there is always need for improvement and this is what the management isn't realizing and working on. This needs immediate attention and action in terms of doing researches on it and formulates strategies in order to make this scheme better or of whatever is left of it. There shall be studies done in this regard to identify the key areas of issues and challenges for this scheme and back the same with facts and figures. These will help in the understanding what the success factors are for BIPS that need work and immediate action for better execution of the scheme.

\section{CONCLUSIONAND RECOMMENDATIONS}

It can be concluded that the introduction of this scheme has provided a positive influence on the reduction of poverty to an extent and at the same time have provided a platform for women empowerment which resulted in rise of living standards of the individuals in the rural regions of the country. There has been an increasing a great number of women who have received benefit from this scheme and are being provided with protection from going into worse Moreover, these benefits didn't limit to women only, but also to their families as well where they have an increased level of consumption in regards of food, health and education via means of cash assistance. Their living standards have improved as well. This program has provided a framework where women can safeguard their basic needs and enhance the economic conditions as well. They have provided the women with the options to practice their skills and abilities in decision and plan making and be in a better position to take care of their families as well. This has increased the importance of the role of the women of how they can take part in the economic drive and make s good source of income for themselves and their families. This scheme has enabled the rise of income generating facilities and activities for livelihood and economic progress.

However then at the same time it is seen that this opportunity can be provided to more women out there but it hasn't been possible yet due to lack in the scheme and result of no attention on these lacking. This is unfortunately evident in the country of Pakistan that many such schemes have a good start but as they are progressed further, there is decrease in efforts to maintain and increase the enhancement of such schemes. Then these lacking reduce the effectiveness of such programs and the goals aren't being achieved. This gives rise to inefficiency and ineffectiveness because of which such schemes are prone to disasters and failure which is indeed a very unfortunate thing. It is highly advised that the concerned parties and regulatory bodies take necessary actions and make efforts to make such initiatives successful and give way for formulation of similar and innovative programmes and schemes. Steps 
shall also be taken by them to deal with the challenges and incompetency identified and described earlier in the report.

\section{REFERENCES}

Ali, S. S., Tahir, S., \& Arif, G. M. (1999). Dynamics of Growth, Poverty, and Inequality in Pakistan. The Pakistan Development Review, 38(4), 837-858.

Amjad, R., \& Kemal, A. R. (1997). Macroeconomic Policies and their Impact on Poverty Alleviation in Pakistan. The Pakistan Development Review, 36(1), 39-68.

Arif, G. M. (2006). Targeting Efficiency of Poverty Reduction Programs in Pakistan. Pakistan Resident Mission Working Paper No. 4, May. Islamabad: Asian Development Bank.

Asian Development Bank. (2002). Country Strategy Progress. 2002-2006, Manila: ADB. International Fund for Agricultural Development. (2001). Rural Poverty Report 2001: The Challenge of Ending Rural Poverty. Oxford: Oxford University Press.

Bahram, Aqsa \& Phuong Dung, Ahmad \& Waqar, Zahoor \& Bibi, Doan \& Shah. (2017). The Effect of Benazir Income Support Program on Poverty Reduction: Case Study of the Two Villages in District Swat Pakistan.

Benazir Income Support Programme. Retrieved on July 25, 2011 from http://www.bisp.gov.pk

Chaudhry, \& Imran, S. (2003). An Empirical Analysis of the Determinants of Rural Poverty in Pakistan: A Case Study of Bahawalpur District with Special Reference to Cholistan. Unpublished Ph.D. Thesis, the Islamia University of Bahawalpur: Pakistan.

Chaudhry, \& Imran, S. (2009). An Empirical Analysis of the Determinants of Rural Poverty in Pakistan: A Case Study of Multan District.Thesis, the Islamia University of islamabad: Pakistan.

Chaudhry, I., Malik, S., \& Imran, A. (2006). Urban Poverty and Governance: The Case of Multan City. The Pakistan Development Review, 45(4), 819-830

Chaudhry, Imran, S., Malik, S., \& M., A. (2005). Poverty in Cholistan: Profile and Correlates. Paper Presented at 21st Annual General Meeting and Conference, Pakistan Society of Development Economists: Islamabad, 19th -21st December.

Federal Board of Statistics, Government of Pakistan. (2001). Poverty in the 1990s. Islamabad: The Author

International Labor Organization. (2003). Working out of poverty Report of the Director-general in international Labor conference. Geneva: ILO.

Irz, X., Lin, L., Thirtle, C., \& Wiggins, S. (2001). Agricultural Productivity Growth and Poverty Alleviation. Development Policy Review, 19(4), 449-466. doi: 10.1111/1467-7679.00144

Jafri, \& Younas, S. M. (1999). Assessing Poverty in Pakistan in a Profile of Poverty in Pakistan. Mahbub-ul-Haq Center for Human Development: Islamabad.

Kemal, A. R. (1995). Poverty Alleviation in Pakistan: An Evaluation of Public Strategies and Policies Adopted for Poverty Alleviation. Organized by Institute of Policy Studies: Islamabad.

Khan, S. (2009). Poverty Reduction Efforts: Does Microfinance Help? John Hopkins School of Advanced International Studies Review. The Johns Hopkins University Press, 29(2), 147157.

Malik, S. (1996). Determinants of Rural Poverty in Pakistan: A Micro Study. The Pakistan Development Review, 35(2), 171-187.

Ministry of Finance, Government of Pakistan. (2003). Accelerating economic growth \& reducing poverty: The road ahead (Poverty Reduction Strategy Paper). Islamabad: The Author

Planning Commission, Government of Pakistan. (2005). Medium Term Development Framework 2005-10. Islamabad: The Author

Todaro. Michael, P. (2000). Economic Development 7th edition. Addison Wesley, 170.

United Nations World Food Programmes. Retrieved in August 2011 from http://www.wfp.org.pk

World Bank. (2000). Poverty in Pakistan: Issues, Priorities and Policy Options: a Concept Note, Paper 
IBT Journal of Business Studies

Presented at a Seminar. Islamabad: World Bank.

World Bank. (2008). World Development Report 2008: Agriculture for Development. New York: Oxford University Press.

World Food Programme. (2011). WFP's Role in social protection and safety nets: A strategic evaluation. Retrieved from

http://home.wfp.org/stellent/groups/public/documents/reports/wfp235864.pdf 